\title{
Psicologia e a Política de Direitos: Percursos de uma Relação
}

\author{
Vinicius Furlan \\ Pontifícia Universidade Católica, SP, Brasil.
}

Resumo: Este é um ensaio que visou recuperar os percursos da relação da Psicologia com a Política de Direitos no período da ditadura civil-militar e da atualidade. Para tanto, recorremos à pesquisa bibliográfica e à pesquisa documental. A primeira busca recuperar os processos históricos desta relação, fazendo um resgate das práticas da Psicologia durante o período da ditadura até o atual momento. A segunda objetiva encontrar elementos deste percurso e que revelam como tem se dado a relação da Psicologia com a Política de Direitos em nosso tempo. A partir das investigações, observa-se que a Psicologia serviu e andou de mãos dadas com a ditadura militar, contribuindo com a aplicação de testes e práticas de tortura aos presos políticos. Apesar de esta prática ter sido hegemônica nesse período, a Psicologia conformava-se enquanto um campo conflituoso de saberes, fazeres e posicionamentos político-ideológicos e, com os processos de democratização do país, ela também se reorientou e se reinventou, assumindo como norte um compromisso ético e político com a construção de uma sociedade mais justa e igualitária e com a Política de Direitos. Não obstante este compromisso ter tomado conta da Psicologia, a partir de articulações da atuação da Psicologia durante a ditadura e em nosso tempo, identificam-se heranças em seu seio que foram deixadas pela ditadura, como as violações de direitos em instituições e entidades em que o profissional da Psicologia atua e contribui para tais violações, bem como quando apoiam projetos que estão na contramão da Política de Direitos, como do suposto projeto da "cura gay".

Palavras-chave: Psicologia, Direitos Humanos, Ditadura Civil-militar.

\section{Psychology and the Rights Policy: Paths of a Relationship}

\begin{abstract}
This essay intends to recover the paths of the relationship between Psychology and the Rights Policy, through a bibliographical and documentary research. The first one seeks to recover the historical processes of this relationship, rescuing the practices of Psychology during the period of the dictatorship up to know. The second aims to find elements of this course and to reveal how the relationship between Psychology and the Rights Policy in our time has been given. From the investigations, it is observed that Psychology served and went hand in hand with the military dictatorship, contributing with the application of tests and practices of torture to the political prisoners. Although this practice was hegemonic in that period, Psychology was a conflictive field of political-ideological knowledge, actions and positions, and, with the country's democratization processes, it also reoriented and reinvented itself, assuming as a guide an ethical and political commitment with the construction of a more just and egalitarian society and with the Rights Policy. Despite Psychology preserves this ethical and political commitment, it is possible to identify inheritances left by the dictatorship, such as rights violations in institutions and entities in which Psychology professionals act and contribute to such violations, as well as the support by some psychologists to projects that are divergent from the Rights Policy, such as the supposed "gay conversion therapy".
\end{abstract}

Keywords: Psychology, Human Rights, Civil-Military Dictatorship. 


\title{
Psicología y Política de Derechos: Caminos de una Relación
}

\begin{abstract}
Resumen:Este es un ensayo que pretende recuperar los caminos de la relación de la Psicología con la Política de Derechos. Para ello, recurrimos a la investigación bibliográfica y a la investigación documental. La primera busca recuperar los procesos históricos de esta relación, haciendo un rescate de las prácticas de la Psicología durante el período de la dictadura hasta el momento actual. La segunda tiene el objetivo de encontrar elementos de este camino que revelan cómo se ha dado la relación de la Psicología con la Política de Derechos en nuestro tiempo. A partir de las investigaciones, se observa que la Psicología sirvió y anduvo de la mano de la dictadura militar, contribuyendo con la aplicación de pruebas y prácticas de tortura a los presos políticos. A pesar de que esta práctica fue hegemónica en ese período, la Psicología se conformaba como un campo conflictivo de saberes, prácticas y posicionamientos político-ideológicos, y, con los procesos de democratización del país, ella también se reorientó y se reinventó, asumiendo como orientador un compromiso ético y político con la construcción de una sociedad más justa e igualitaria y con la Política de Derechos. A pesar de que este compromiso ha tomado cuenta de la Psicología, a partir de articulaciones de la actuación de la Psicología durante la dictadura y en nuestro tiempo, se identifican herencias que fueron dejadas por la dictadura en su seno, como las violaciones de derechos en instituciones y entidades en las que el profesional de la Psicología actúa y contribuye a tales violaciones, así como el apoyo a proyectos que están en contra de la Política de Derechos, como del supuesto proyecto de la "curación gay".
\end{abstract}

Palabras clave: Psicología, Derechos Humanos, Dictadura Cívico-Militar.

\section{Introdução}

Depois de um longo histórico da Psicologia no país, a instância representativa da categoria, Conselho Federal de Psicologia, propôs a premiação de trabalhos que abordassem a temática da relação da Psicologia com os Direitos Humanos, bem como os impactos do drástico período histórico do país vivenciado sob a égide da ditadura-civil militar (1964-1985) sobre a Psicologia na atualidade ${ }^{1}$.

Neste sentido, este ensaio teórico tem como objetivo discutir passagens acerca da relação da Psicologia com a Política dos Direitos nos períodos da ditadura civil-militar e da atualidade. Visou-se discorrer sobre algumas práticas da Psicologia enquanto profissão e de suas entidades representativas, como o Sistema Conselhos de Psicologia e o Sindicato dos Psicólogos.

Por políticas de direitos compreendemos, de acordo com o sociólogo Santos (2012; 2013), uma política orientada para a garantia e efetivação dos direitos humanos sustentada na concepção de que todos os humanos são cidadãos, portanto, sujeitos de diretos e, assim, busca a construção de uma sociedade mais justa e igualitária para todos, respaldando-se nos interesses da coletividade e do bem comum. Esta política, por sua vez, não se dá apenas enquanto aparato institucionalizado do Estado, mas implica na busca constante de constituir e efetivar uma política institucional dos direitos humanos: que recubra todas as populações, tanto por parte dos interesses do Estado como por meio de mobilizações e posicionamentos incansáveis da sociedade civil, e que se efetive nas relações de sociabilidade intersubjetivas em que se forjam as subjetividades por vias das dimensões do reconhecimento.

Para tanto, como método para nossa reflexão, recorremos a dois caminhos: o da pesquisa bibliográfica e o da pesquisa documental (Gil, 1987). O primeiro busca recuperar, a partir de fontes secundárias já trabalhadas por outros autores, os processos históricos desta relação, fazendo um resgate desde as práticas da Psicologia durante o período da ditadura até o atual momento. O segundo objetiva encontrar elementos deste percurso, a partir de materiais ainda não trabalhados por outros autores como sites, jornais, anais de congressos etc. que citamos à guisa de ilustração - e que revelam como tem se dado a relação da Psicologia com a Política de Direitos em nosso tempo.

${ }^{1}$ Este texto foi elaborado, portanto, no ano de 2013, para concorrer a tal premiação, momento em que ainda cursava a graduação. 
Assim, a partir destes objetivos e investigações, o texto comporta uma discussão que busca recuperar os percursos históricos das práticas hegemônicas da Psicologia desde o tempo da ditadura civil-militar bem como de nosso tempo, buscando elencar, por meio da bibliografia e recursos documentais, os elementos que indicam os modos com que a Psicologia tem se articulado com a Política e os Direitos.

\section{"Num tempo, página infeliz da nossa história"}

A Psicologia se configura como uma imensa pluralidade e heterogeneidade de vertentes teóricas e epistemológicas que constituem o que tem se costumado a chamar de psicologias. Cada uma destas psicologias possui construtos teóricos e perspectivas epistemológicas que orientam a prática (ou práxis) a qual a(o) psicóloga(o) está vinculada(o), o que, por sua vez, a conforma enquanto um campo conflituoso de saberes e fazeres, que se norteiam por diferentes posicionamentos ideológicos e políticos intercambiados por grupos, associações e instituições.

Neste sentido, as relações da Psicologia com a Política, por meio de suas práticas e saberes, são atravessadas por estes diferentes posicionamentos, o que implica reconhecer que, embora os conflitos inerentes a seu campo por conta de tais diferenças ideológicas e políticas, de tempos em tempos, a relação entre Psicologia e Política se transforma e isto reverbera em processos de ressignificação de seus construtos teóricos, seus fazeres e posicionamentos político-ideológicos.

Assim, recuperar a memória dos meados das décadas de 1960 e 1970 no Brasil é, sobremaneira, uma forma de resgatar um período de nossa história que muito tem se tentado esquecer, por conta de questões políticas e ideológicas. Situar o lugar da Psicologia no seio dessa história permite, portanto, trazer à memória uma "outra" narrativa histórica da Psicologia que tem ficado ocultada ou silenciada.

Nos tempos de ditadura, Coimbra (1995) destaca que a prática hegemônica da Psicologia junto à sociedade foi a de adaptar os indivíduos à ordem vigente, ao status quo da sociedade, com vistas a contribuir para o controle dos indivíduos, tornando-os passivos e submissos frente as injustiças da estrutura sociopolítica, legitimadoras do poder e da exclusão social.

Assim, com o golpe militar, "a nova profissão não buscava apenas legitimidade social, mas pretendia mostrar para as classes dominantes atuantes no Brasil que a psicologia não era uma ameaça à ordem social” (Lacerda Junior, 2013, p. 220).

De acordo com Patto (2003, p. 14), foi "assim que a Psicologia fez-se discurso ideológico que justifica a desigualdade social transformando-a em desigualdade psíquica individual".

Cabia, pois, à Psicologia realizar diagnósticos psicológicos, a fim de identificar as dificuldades e problemas de ajustamento dos indivíduos e colaborar para a sua solução, ajustando-os aos seus respectivos contextos.

Uma característica marcante da Psicologia era a sua restrição e isolamento à prática do contexto clínico. Em que pese os ambientes da escola e da indústria também sejam característicos dessa época, sendo a Psicologia, nestes contextos, um instrumento de exclusão.

Outra marca forte da Psicologia era sua vinculação com a elite da sociedade, já que a classe excluída dos bens culturais e econômicos era privada de seus serviços. Tinha-se, assim, uma Psicologia elitizada e elitista, contribuindo para a perpetuação da exploração desta classe social sobre as demais.

A Psicologia, portanto, era utilizada como um instrumento de dominação social para docilizar e domesticar os sujeitos humanos.

Esta prática da Psicologia estava orientada por uma compreensão epistemológica e metodológica da ciência sustentada pela filosofia positivista; tinha-se então uma compreensão naturalizante e biologizante do homem, de uma ciência humana pautada na neutralidade e objetividade, num tecnicismo científico controlador e reducionismo psicológico, reificante das questões sociais e humanas tidas como a-históricas.

Conforme destaca Coimbra (1995), nessa época,

[...] a formação "psi", em geral, traz certas características modelares instituídas e tão bem marcadas; como, em nossa formação, predomina o viés positivista, onde se tornam hegemônicos os conceitos de neutralidade, objetividade, cientificidade e tecnicismo; onde, nos diferentes discursos e práticas, o homem e a sociedade são apre-

${ }^{2} \mathrm{O}$ texto está estruturado em três tópicos, cada um leva como título versos de letras de músicas que estão relacionadas com a discussão e a história a qual se narra. No caso, os dois primeiros títulos foram retirados de músicas de Chico Buarque, a saber, "Vai passar” e "Cálice”; o último foi retirado da música "Latinoamérica" do grupo porto-riquenho Calle 13. 
sentados como "coisas em si", abstratos, naturais e não produzidos historicamente (p. 9).

Oliveira (2013) destaca que a ditadura foi condicionante para a configuração da prática liberal da Psicologia e que esta configuração era resultante tanto de um "cerceamento à liberdade de expressão, como censura a todos os aspectos relativos ao social e à dimensão política de vida em sociedade” (p. 74). Isto, por sua vez, marcava uma Psicologia que não podia fazer leitura crítica da realidade social.

Foi neste contexto que a Lei $n^{\circ}$ 5.766/71 (Brasil, 1971) que cria o Conselho Federal de Psicologia (CFP) e os Conselhos Regionais foi instaurada. Durante o momento que o país passava pela ditadura declarada, sem disfarces, tido como o pior período do regime militar (1971-1974), em que se utilizava a tortura e a violência como instrumento oficial da política, os Conselhos Regionais receberam um papel policialesco e autoritário de fiscalizadores com relação à prática profissional dos psicólogos (Coimbra, 2009).

Coimbra (2009) destaca que a Psicologia serviu e andou de mãos dadas com a ditadura, tanto que o CFP homenageou Emílio Garrastazu Médici dando-lhe diploma de psicólogo honorário e, não por acaso, seu grande boom no Brasil se deu neste período. Vale lembrar que Médici, após o Ato Institucional $\mathrm{n}^{\circ} 5$ comandou o período mais repressivo do Regime Militar, marcado por perseguições, prisões e assassinatos de pessoas que faziam parte da oposição.

Por outro lado, parte das(os) profissionais de Psicologia que não estavam de mãos dadas com o regime implicava em opôr-se a ele. Em estudo realizado por Scarparo e Ozorio (2009) acerca do Conselho Regional de Psicologia (CRP) da $7^{\text {a }}$ região no período da ditadura, os participantes da pesquisa, que atuaram neste Conselho durante 1981 a 1984, afirmaram que em suas práticas e pautas não era dada ênfase nas questões políticas.

Nos estudos de Hur $(2007 ; 2012)$ fica evidente que o modus operandi das Associações e do Sindicato de Psicologia se orientava apenas por preocupações técnicas da profissão e não "políticas". O pesquisador relata um episódio do sindicato dos psicólogos em que lhe foi solicitado um posicionamento diante do assassinato de Vladimir Herzog, acompanhando Sindicatos de outras categorias e movimentos que se solidarizaram. O Sindicato de Psicologia decidiu por não se manifestar, alegando que, por Herzog não ser psicólogo, qualquer manifestação em sua solidarie- dade se trataria de "posicionamento político" e a eles cabiam apenas discutir questões técnicas, corroborando, assim, a lógica corporativista e de subserviência ao Estado, como previa o Estatuto de sua fundação.

Não obstante, é importante demarcar que esta é uma parcela da representatividade da Psicologia e estamos tratando aqui da sua prática hegemônica, pois muitos psicólogos, psicólogas, estudantes de Psicologia, professores e professoras, militaram e opuseram-se ao regime, sendo até presos e torturados.

De modo enfático, Coimbra (2009) ressalta que também serviram o regime, mesmo que indiretamente, aquelas(es) psicólogas(os) que ignoravam as condições sociopolíticas do país e exerciam práticas extremamente fascistas e conservadoras.

Coimbra destaca ainda que, durante o regime, a Psicologia criou um projeto chamado de "Perfil psicológico do terrorista brasileiro", para dizer que aqueles que se opunham ao regime militar eram pessoas desestruturadas, desajustadas e vinham de famílias problemáticas: "Os psicólogos aplicavam anamnese, testes de nível mental, um teste de frustração, testes de personalidade, testes projetivos etc., e traçavam o perfil do opositor político" (Coimbra, 2009, p. 4).

[...] houve profissionais "psi" que apoiaram e respaldaram a patologização dos que lutavam contra a ditadura, classificando-os como "carentes", "desestruturados", ou seja, "doentes", por meio de uma pesquisa, "O Perfil Psicológico do Terrorista Brasileiro", que usou uma série de testes psicológicos aplicados a presos políticos. Alguns desses profissionais forneceram laudos psiquiátricos e psicológicos de militantes presos, entre 1964 e 1978, também patologizando-os. Uma prática mais indigna ainda foi a dos profissionais que davam suporte às torturas, orientando os torturadores acerca dos limites dos presos, para continuarem sendo torturados ou não, como foi o caso de Amílcar Lobo, que, à época, fazia formação psicanalítica. Muitos profissionais, como psicólogos, psiquiatras, médicos, legistas, advogados colaboraram para que a tortura e o terrorismo de Estado funcionassem de forma eficiente e produtiva; ainda hoje, continuam respaldando processos de exclusão e estigmatização, com os seus saberes e suas práticas, no Brasil e em outros países. [...] Não por acaso, foi nos anos de 1970 que ocorreu, em nosso país, o "boom” das práticas psi, em especial 
da Psicologia e da Psicanálise; práticas que afirmavam uma Psicologia assistencialista, cientificista, objetiva e neutra. Tais práticas fortaleceram, além do essencialismo e do individualismo, uma psicologização do cotidiano: tudo o que ocorria no mundo era remetido para explicações psicológico-existenciais. E, ainda, através de intimidação e do familiarismo, as práticas psi andaram de mãos dadas com a ditadura, ao deixar de considerarem o contexto histórico, político e social na análise das situações "psi" (Coimbra, s.d., p.p. 15-16).

Assim a Psicologia teve participação direta no aparato repressivo da ditadura militar brasileira. Essa participação assemelhava-se àquela que vários médicos tiveram, em que não só acompanhavam os presos políticos torturados, mas também ministravam treinamentos a torturadores e elaboravam laudos psicológicos de presos políticos, sem fazer qualquer menção às inúmeras sessões de torturas às quais eles eram submetidos (Coimbra, 2011).

Para a autora, as práticas psicológicas realizadas junto ao governo militar tinham objetivos contrários a qualquer possibilidade de se pensar nas condições subjetivas dos prisioneiros e torturados por militares e, com argumentos de defesa da ordem proporcionada pelo regime militar, acreditavam na necessidade de traçar um perfil daqueles que se mostravam contrários ao regime.

Vemos assim que analogamente ao aparato jurídico que, de acordo com Agamben (2004), possuía uma relação instituída com um sistema de estado de exceção - representado na figura de uma ditadura -, o governo ditatorial do nosso país também teve, disposto a seus serviços, o aparato da categoria da Psicologia.

Isto ratifica, por sua vez, conforme assinala Oliveira (2013), que o clima político de seu tempo é determinante direto daquilo que resulta nas práticas e orientações do aparato da categoria da Psicologia.

Nossa reflexão até aqui permite observar o modo como a Psicologia se relacionava, em sua prática hegemônica, com as questões políticas e os direitos durante $o$ período da ditadura, ficando evidente que nalguns casos contribuiu para as violações dos direitos humanos tendo posicionamentos políticos como sendo "não políticos".

Iremos a partir de agora refletir acerca de construtos psicológicos que buscaram produzir posicionamentos críticos e políticos e práticas diferenciadas frente às que configuravam a prática hegemônica da Psicologia daquele período, e como estes construtos e posicionamentos foram determinantes para a reorientação e reinvenção de seu panorama atual, embora sequelas da atuação da Psicologia que serviu a ditadura ainda estejam imbricadas em determinadas práticas e saberes.

\section{"Esse pileque homérico no mundo"3}

Como destaca Lacerda Junior (2013), durante a ditadura, houve diversos setores da sociedade civil que se organizaram em lutas contra o capital e o regime militar. Este processo, por sua vez, também atingiu a Psicologia, criando cisões, crises e transformações. Assim, surgiram novos construtos teóricos e práticas na Psicologia brasileira e na América Latina.

É importante demarcar, neste sentido, o papel da Psicologia Social e da Psicologia Política neste processo, que naquele período, em toda a América Latina, começaram a apontar para a necessidade de se construir uma Psicologia de orientação crítica e com compromisso ético-político demarcado com a transformação dos problemas sociais vividos pelas classes populares (Hur \& Lacerda Jr, 2016; Lima, Ciampa \& Almeida, 2009).

Neste sentido, tal proposição se orientou (a) por uma compreensão ontológica do homem enquanto ser histórico e social, tendo a práxis como orientadora de suas ações, e assumiu, naquele momento, um caráter político com a redemocratização da sociedade durante a ditadura. Esta proposição política e crítica teve papel essencial para a reorientação do olhar e compreensão da Psicologia acerca das questões sociais, do compromisso ético e político com a construção do bem comum e com a construção de uma sociedade mais justa e igualitária.

Não obstante, é importante lembrar que não apenas a Psicologia Social e Política tiveram papel na reorientação da compreensão de homem, sociedade

${ }^{3} \mathrm{O}$ título deste tópico, como já exposto, foi retirado de um trecho da música de Chico Buarque "Cálice”; canção que foi produzida nos tempos de ditadura e que foi censurada, devido aos compositores Chico Buarque e Gilberto Gil, metaforicamente, fazerem alusão à situação que sociedade vivenciava durante o regime. O "pileque homérico" trata das inquietações, indagações e contestações do homem sobre a vida e outras possibilidades de formas de vida e, especificamente na música, se refere ao desejo de liberdade dos cidadãos do regime ditatorial. Recuperamos este trecho para ser um dos títulos do artigo por conta de estarmos tratando desta história e das inquietações que mobilizaram os cidadãos a se posicionarem frente as injustiças daquele governo, bem como por fazermos analogia com as indagações de certas vertentes da Psicologia que possibilitaram a construção de outros posicionamentos políticos e éticos em seu seio. 
e compromisso ético-político da Psicologia, mas também outras. Todavia, elas foram pioneiras e trouxeram contribuições importantíssimas neste sentido.

Assim, esta emergência de posicionamentos críticos em relação à situação da população vivida naquela época culminou também no desenvolvimento da Psicologia Social Comunitária, por meio da qual profissionais vinculados a movimentos contrários do regime ditatorial, preocupados com a construção de novas práticas críticas às instituições sociais conservadoras, iniciaram uma nova relação com as populações subalternas, buscando criar estratégias para a garantia de direitos humanos e do exercício de cidadania.

Estas novas proposições e práticas marcaram profundamente a orientação da política da Psicologia que, em seu panorama atual, tem se implicado e assumido sérios compromissos com a construção do bem comum, com os direitos humanos, com as políticas públicas e com o político.

Como um dos fatos reveladores deste interesse e preocupação da Psicologia, podemos citar a criação da Comissão dos Direitos Humanos do CFP (oficializada na Resolução CFP no 11/1998), cujas funções, conforme $\mathrm{o}$ artigo $2^{\circ}$ da Resolução, demarcam que:

Art. $2^{\circ}$ - São atribuições da Comissão de Direitos Humanos do Conselho Federal de Psicologia: I - incentivar a reflexão sobre os direitos humanos inerentes à formação, à prática profissional e à pesquisa em psicologia; II - intervir em todas as situações em que existam violações dos direitos humanos que produzem sofrimento mental; III - participar de todas as iniciativas que preservem os direitos humanos na sociedade brasileira; IV - apoiar o movimento internacional dos direitos humanos; $\mathrm{V}$ - estudar todas as formas de exclusão que violem os direitos humanos e provoquem sofrimento mental.

Isto também está previsto pelo Código de Ética Profissional do Psicólogo (Resolução CFP no 10/2005), logo no início de seus Princípios Fundamentais, ao orientar que às(aos) psicólogas(os) cabe respaldar suas ações nos valores da Declaração Universal dos Direitos Humanos e trabalhar no sentido de eliminar todas as formas de violência da sociedade.

I. O psicólogo baseará o seu trabalho no respeito e na promoção da liberdade, da dignidade, da igualdade e da integridade do ser humano, apoiado nos valores que embasam a Declaração Universal dos Direitos Humanos.

II. O psicólogo trabalhará visando promover a saúde e a qualidade de vida das pessoas e das coletividades e contribuirá para a eliminação de quaisquer formas de negligência, discriminação, exploração, violência, crueldade e opressão.

Além destefator temos observado que estáhavendo (e isto tem sido um processo gradativo) um grande interesse por parte das(os) profissionais de Psicologia em participar e adentrar espaços em que se discute e luta pela promoção, proteção e garantia dos direitos humanos (Furlan, \& Pelissari, 2013). Espaços como: movimentos sociais, fóruns de discussões, conselhos de controle social, centros de referências, espaços de construção de políticas públicas etc., bem como espaços em que se pautam temáticas como saúde, direitos das crianças e adolescentes, direitos do idoso, direitos da mulher, da família, medicalização da sociedade e da educação, antimanicomialismo, saúde do trabalhador, direito à política, direito à cidadania, entre outros.

Isto é observado não apenas nos contextos de inserção prática do profissional da Psicologia, mas também na Psicologia produzida e ensinada no meio acadêmico-universitário, onde se vê uma grande quantidade de núcleos e grupos de estudos e pesquisas que se debruçam acerca das temáticas expostas acima, em que tais pesquisas não apenas têm esses campos de forças e contradições como meros objetos de estudo para coleta de dados e produção de conhecimento, mas como um campo para o exercício da participação política e transformação social.

Yamamoto (2012) destaca que na pesquisa nacional acerca da profissão do psicólogo realizada pela Anpepp (Associação Nacional de Pesquisa e Pós-Graduação em Psicologia), publicada em 2010, foi constatado que aproximadamente $40 \%$ dos psicólogos que participaram do estudo trabalham no campo das políticas sociais.

Este interesse ainda é notado quando na " 2 a Mostra Nacional de Práticas em Psicologia”, ocorrido em 2012, após 12 anos do acontecimento da primeira, tivemos como tema "Compromisso com a Construção do Bem Comum”, e para discutir como fazermos isso contamos com a presença de: Pedro Pontual, ligado à Secretaria-geral da Presidência da República no Departamento de Participação Social; Paulo Vanuchi, 
principal responsável pelo Plano Nacional de Direitos Humanos; Pedro Paulo Gastalho de Bicalho, atual coordenador da Comissão Nacional de Direitos Humanos do CFP; Marcus Vinícius de Oliveira, discutindo a posição do Sistema Conselhos de Psicologia acerca do Direito aVerdade; e outras figuras importantes que partilham e lutam pela conquista de um país mais justo, além de outros temas que compuseram as mesas e as diversas discussões que tratavam do bem comum, da conquista de direitos humanos e outros direitos, de controle social, de gestão pública e outros. Em uma das salas foi apresentado um vídeo sobre os direitos humanos, organizado pela Comissão Nacional de Direitos Humanos do CFP e intitulado "Direitos Humanos, Nossos Direitos", que fazia uma homenagem a Vladimir Herzog. Aqueles que por ela passaram não saíram sem ter despertado uma inquietação e indignação frente as injustiças e violências cometidas nesse país.

A "2a Mostra Nacional de Práticas em Psicologia” revelou, portanto, o imprescindível e necessário compromisso que a Psicologia, em seu panorama atual, tem assumido com as políticas públicas, os projetos sociais, os direitos humanos, ou seja, o compromisso com o bem comum para a construção uma sociedade mais justa e igualitária.

Temos ainda a criação de outras instâncias e eventos que se orientam neste sentido. Podemos citar: a criação do Crepop (Centro de Referência Técnica em Psicologia e Políticas Públicas) em 2006, que revela o interesse e a demanda que tem sido apresentada à Psicologia para atuar no âmbito das Políticas Públicas, principalmente no que se refere à redução da desigualdade social; a criação dos Seminários de Psicologia e Políticas Públicas e de Psicologia e Direitos Humanos; além de tantos outros exemplos.

Isto mostra como a Psicologia tem se orientado pelo compromisso com os direitos dos cidadãos e com a construção de uma sociedade mais justa e igualitária, travando uma resistência com os drásticos impactos gerados pelo capital sobre a vida das pessoas e uma luta com a falta de investimento em políticas públicas para a garantia de uma vida digna para os cidadãos.

Para Pereira (2007), o fato de a Psicologia adentrar o campo do público é uma forma contra-hegemônica de se fazer Psicologia. De acordo com Carmo (2001), o compromisso dos psicólogos com as políticas públicas tem a ver com sua inserção social enquanto exercício de sua cidadania.
Essas reorientação e transformação da Psicologia, de acordo com Antunes (2012), têm a ver particularmente com o processo de organização da categoria, em que

Muitas das entidades representativas da Psicologia assumiram papéis de grande relevância na transformação da Psicologia no Brasil, fomentando a crítica e proporcionando condições para o debate e para a busca de soluções e possibilidades de superação daquela Psicologia limitada e elitista, em direção à constituição de uma ciência e de uma profissão radicada em sua realidade e com ela comprometida (p. 62).

Observa-se, portanto, como já vimos no primeiro tópico, conforme Oliveira (2013), o clima político de seu tempo é determinante direto das práticas e orientações de uma categoria profissional, em nosso caso da categoria das(os) psicólogas(os). Assim, como as mobilizações dos movimentos, associações etc., que possibilitaram os processos de democratização do país e novos rumos a política institucional, no seio da Psicologia também houve mobilizações, conflitos internos e posicionamentos crítico e políticos que possibilitaram com que este campo de saberes e fazeres pudesse se reinventar e reorientar, embora não em sua totalidade, seu compromisso social e político eticamente voltados a Políticas dos Direitos, em que se devem basear os valores democráticos.

\section{"Aquí se respira lucha"?}

Apesar da preocupação e do interesse da Psicologia em discutir, colaborar e ocupar espaços em que se luta por direitos, se discute e se constroem políticas públicas, em livro de publicação do CRP-SP, a coordenadora da Comissão de Direitos Humanos (de 2009 a 2010) do mesmo Conselho destaca que ainda

[...] emerge das práticas profissionais e das denúncias do movimento de defesa dos direitos humanos, uma série de situações que revelam a ausência da garantia dos direitos humanos em diversas instituições ou entidades em que o profissional da psicologia atua, particularmente aquelas em que há privação de liberdade (sistema prisional, hospitais psiquiátricos, abrigos 
para crianças e idosos, Fundação CASA, entre outras). [...] através da interlocução com várias dessas entidades acusadas de realizar violações de direitos humanos pode-se observar que os profissionais da psicologia em algumas situações manifestaram conivência com as violações e violências propagadas na instituição. Em alguns casos, inclusive defendendo o uso de práticas como a tortura, castigo e humilhações para coibir determinados comportamentos incompatíveis com as regras da entidade (Sposito, 2011, p. 17).

Este tipo de prática dos profissionais da Psicologia nestas instituições, sejam elas filantrópicas, privadas, ou públicas, em que se viola os direitos humanos e se contribui para o sofrimento e adoecimento psíquico, herdamos dos tempos de ditadura.

A atuação dos profissionais da Psicologia em instituições que têm como objetivo lucrar com aquilo que é sofrimento humano e que camufla esse objetivo por trás de um discurso altruísta nos remete às práticas da Psicologia durante o regime militar.

Geralmente as práticas cometidas que violam os direitos humanos, sejam de agressão, contenção corporal, xingamento, ofensas, intimidações, humilhações e outras, ocorrem por conta da não submissão à norma institucional ou a "àquele que manda" etc. E os profissionais da Psicologia têm contribuído com este tipo de prática, muitas vezes sendo os responsáveis por fazer com que os sujeitos institucionalizados sejam cada vez mais domesticados à ordem institucional e por gerar sofrimento psíquico. Quando isso não ocorre, o profissional da Psicologia que está na instituição acaba por se institucionalizar e tal prática passa a ser entendida como natural.

Vemos ainda práticas do período ditatorial que perduram dentro dos contextos clássicos da Psicologia (clínica, escola e indústria), como: o isolamento de alguns profissionais da Psicologia no consultório clínico, atendendo apenas a elite da sociedade; a atuação dentro da escola a partir de uma perspectiva clínica, realizando diagnósticos e contribuindo para a produção de deficiências e crianças "problemas", culpabilizando a criança e a família e, com isso, obscurecendo as contradições intraescolares e sociais; e a atuação do psicólogo dentro da indústria como mero aplicador de testes para seleção de pessoal e assim contribuindo para excluir o trabalhador do mercado do trabalho, entendo-o como não capacitado.
Em outro exemplo, podemos citar o estudo de Costa, Oliveira e Ferraza (2014), que demonstra o distanciamento político ou os posicionamentos políticos não ligados aos direitos humanos de muitos profissionais "psi" ao tomarem as polêmicas que envolveram as propostas do antigo presidente da Comissão de Direitos Humanos na Câmara dos Deputados, que ficaram conhecidas como "cura gay", e que afetariam diretamente as práticas e discursos das(os) profissionais da Psicologia. As(os) psicólogas(os), assegurados pela Resolução do CFP, publicada em 1999, não podem colaborar com eventos e com a divulgação de serviços que ofereçam tratamento para a suposta "cura" da homossexualidade, além de serem vedados de participar de manifestações que reforcem preconceitos sociais em relação às práticas homoafetivas. Tal projeto visava derrubar a resolução do CFP com o intuito de assegurar a prática de profissionais "psi" que divulgam a possibilidade de "tratarem" homossexuais e que alegam promoverem o suposto bem-estar para a família e para a nação brasileira. Diante da polêmica causada pelo referido projeto, inúmeros profissionais se posicionaram como contrários às propostas do presidente da Comissão de Direitos Humanos; no entanto, muitas(os) psicólogas(os) também saíram em apoio ao projeto, alegando que sofriam perseguições do conselho de classe devido ao posicionamento em relação às relações homoafetivas. O distanciamento desses profissionais em relação às noções de direitos humanos e cidadania ficam evidentes ao desconsiderarem as possibilidades de que projetos como aqueles poderiam provocar mais atos homofóbicos, agressões, torturas e mortes apenas pela orientação sexual de diversos indivíduos no país, bem como revela ainda concepções de homem naturalizantes e biologizantes e ideais moralistas de família e das relações afetivas.

Esta contradição das práticas no seio da Psicologia

Trata-se da coexistência de uma Psicologia que avançou para uma ampliação em seu espectro de ação e que se consolidou como instância social comprometida com a construção de uma sociedade mais justa e igualitária e uma psicologia que ainda se submete a concepções tradicionais e ultrapassadas, que não se atualiza e que atua com base em modelos que já foram analisados, criticados e superados há décadas. O movimento 
histórico é, pois, heterogêneo, e há segmentos que tomam a dianteira do processo, outros que respondem mais tardiamente e outros que resistem (Antunes, 2012, p. 62).

Vemos, portanto, que ainda se faz importante, em nossa prática, se orientar pela indagação levantada por Bicalho, Kinoshita, Castilho e Carvalho (2013) e assumida como campanha pela Comissão Nacional dos Direitos Humanos do CFP: "Em nome da proteção e do cuidado, que formas de sofrimento e exclusão temos produzido?".

Conforme o artigo primeiro da Declaração de 1948, "todos os homens nascem livres e iguais em dignidade e direitos". Todavia, destaca Coimbra (2000), que "sempre estiveram fora desses direitos à vida e à dignidade os segmentos pauperizados e percebidos como 'marginais': os 'deficientes' de todos os tipos, os 'desviantes', os miseráveis, dentre muitos outros" (p. 142).

Isto é reflexo, como afirma o sociólogo Santos (2013), da não efetividade da Política de Direitos Humanos e, apesar de incontestável na linguagem de dignidade humana na hegemonia global, a grande maioria da população é apenas objeto desse discurso e não sujeitos de direitos humanos de fato.

Como comenta Teles (2012), os segmentos menos favorecidos socialmente e desprovidos de recursos estão, na mesma medida, desprovidos de direitos, e isto pode ser observado por meio da violência provocada contra os moradores de Pinheirinho e das "cracolândias", sustentada por uma lógica espúria dos interesses do mercado e do capital.

Podemos, nesta perspectiva, observar que a lógica da Política de Direitos se orienta por dois contrapontos: de um lado, visa atender aos interesses do mercado e aos interesses individuais dos donos de capital, de outro, busca garantir uma vida mais digna para toda a população.

Neste sentido, como enfatiza Santos (2012), é preciso cuidado para não cair na armadilha que sustenta os diferentes discursos acerca dos direitos, tendo em vista que eles se orientam por ideologias hegemônicas e contra hegemônicas. As hegemônicas prezam pelo individualismo proprietário, por reproduzir as relações capitalistas, colonialistas e patriarcais; os casos da comunidade de Pinheirinho, a política higienista das "cracolândias" e o genocídio dos povos indígenas se prestam bem como exemplos desta forma ideológica, que se valem pelos interesses individuais e econômicos.
As contra-hegemônicas buscam oferecer concepções alternativas, potencialmente orientadas para a construção de uma sociedade mais justa e igualitária, se respaldando nos interesses da coletividade e do bem comum.

Assim, Teles (2012) se indaga em que medida uma política de inclusão social é compatível com a lógica do mercado determinada pelas elites do sistema financeiro, já que o Estado tem exercido um papel de administrador dos interesses do capital e dos mais ricos, provocando, consequentemente, um crescente constante da desigualdade econômica que contribui para minar sistematicamente a democracia (Peschanski, 2012).

Frente a esta realidade, o psicólogo

será o estrito avaliador da intimidade, aperfeiçoando seus métodos de exame? Ou lembrar-se-á que este sujeito também é sujeito-cidadão, cujos direitos e deveres se constituem no espaço público, território onde perpassam outros discursos e práticas que não o exclusivamente psicológico? (Jacó-Vilela, 1999, p. 17).

Esta autoconscientização ética, portanto, que vem transformando a Psicologia é por demasiado necessária, para inscrevê-la num movimento histórico enquanto uma ciência e profissão que pode contribuir com a dimensão humano-genérica da humanidade (Heller, 2008), ou seja, ela pode e tem buscado se elevar enquanto consciência de "nós" comunidade humana e se inserir na dimensão ética coletiva de colaboração com o bem comum de todos os homens.

A Psicologia que busca, assim, ter um compromisso com a Política dos Direitos pode ter um papel tanto analítico como de intervenção para sua construção, afirmação ou negação, na medida em que pode criar um campo de tensão para planejar estratégias que contribuam para o movimento histórico do humano-genérico (Souza, 2015).

\section{Considerações finais}

A partir de nossas investigações, podemos ver que a Psicologia dos tempos ditatoriais foi determinada pela política de seu tempo, tendo colaborado com aquele sistema de governo, com a criação e aplicação de testes psicológicos, práticas de tortura a presos políticos e silenciamentos frente as formas de injustiças. Isto, por sua vez, revela que, assim como 
outros aparatos, a ditadura teve uma relação instituída com o aparato da categoria da Psicologia.

Em que pese esta forma de fazer Psicologia tenha sido hegemônica naquele período, ela conforma-se enquanto um campo conflituoso de saberes, fazeres e posicionamentos político-ideológicos e, como as mobilizações populares pela democratização do país, parte dos atores ligados à Psicologia - estudantes, profissionais, pesquisadoras (es), docentes etc. - buscou produzir um campo implicado com tais mobilizações e com os processos de democratização, forjando suas práticas psicológicas como formas de resistência, tendo como orientador um compromisso ético-político com as classes populares e com as transformações da realidade social.

Assim, com os processos de democratização do país e os impactos que a política institucional tem sobre as categorias profissionais, a Psicologia também se reorientou e se reinventou, buscando assumir em seus saberes e fazeres um compromisso ético e político com a construção de uma sociedade mais justa e igualitária e com a política de direitos, como podemos ver com os temas de pesquisas e congressos, as preocupações do Sistema Conselhos, os trabalhos em projetos sociais e nas políticas públicas, a criação do Crepop e de Comissões de Direitos Humanos em associações e entidades da Psicologia, dentre outros exemplos.
Não obstante este compromisso ter tomado conta da Psicologia, ainda se identificam heranças das práticas psicológicas ditatoriais que foram deixadas em seu seio, como as violações de direitos em instituições e entidades em que o profissional da Psicologia atua e contribui para tais violações, bem como quando apoiam projetos que estão na contramão da Política de Direitos, como no suposto projeto da "cura gay".

Como podemos ver, a partir das tensões produzidas no seio da Psicologia por conta dos diferentes posicionamentos políticos e ideológicos, ela caminhou no sentido a um processo de autoconscientização ética de compromisso com a política de direitos, embora não em sua totalidade. Temos construído, portanto, em seu panorama atual, um campo que, por um lado, resguarda heranças das práticas do período ditatorial, na medida em que pactua ou contribui com as formas de violações de direitos humanos em instituições e entidades, quando se silencia e colabora com a perpetuação das injustiças sociais e comunga de projetos ideológicos que estão na contramão dos direitos humanos, e que, por outro lado, busca lutar e ter um compromisso ético-político com a política de direitos, com as políticas públicas, visando colaborar com a construção do bem comum e de uma sociedade mais justa e igualitária, na dimensão ética coletiva do "nós" humanos.

\section{Referências}

Agamben, G. (2004). Estado de exceção. São Paulo, SP: Boitempo.

Antunes, M. A. M. (2012). A Psicologia no Brasil: um ensaio sobre suas contradições. Psicologia: Ciência e Profissão, 32(num. esp.), 44-65. https:// doi.org/10.1590/S1414-98932012000500005

Bicalho, P. P. G., Kinoshita, R. T., Castilho, E. W. V., \& Carvalho, G. (2013). Em nome da proteção e do cuidado, que formas de sofrimento e exclusão temos produzido? In Conselho Federal de Psicologia - CFP (Org.), Drogas, direitos humanos e laço social (pp. 17-32). Brasília, DF: CFP.

Brasil. (1971, 20 de dezembro). Lei No 5.766, de 20 de dezembro de 1971. Cria o Conselho Federal e os Conselhos Regionais de Psicologia e dá outras providências. Diário Oficial da União.

Carmo, M. (2001). Políticas públicas como um desafio para os psicólogos. In Relatório do I Seminário Nacional de Psicologia e Políticas Públicas. Salvador, BA: CFP.

Coimbra, C. M. B. (1995). Guardiões da ordem: uma viagem pelas práticas psis no Brasil do "milagre". Rio de Janeiro, RJ: Oficina do Autor.

Coimbra, C. M. B. (2000). Psicologia, direitos humanos e neoliberalismo. Psicologia Política, 1(1), 139-148. Recuperado de http://www.fafich.ufmg.br/ psicopol/psicopol/artigos_pub/artigo_9.pdf

Coimbra, C. M. B. (2009). Mudanças na Psicologia. Jornal do CRP-RJ, 6(21): 3-6.

Coimbra, C. M. B. (2011). Práticas psi no Brasil do “milagre”: algumas de suas produções. In A. M. Jacó-Vilela, F. Jabour, H. B. C., \& Rodrigues, H. B. C., Clio-psyché: história da psicologia no Brasil (pp. 43-53). Rio de Janeiro, RJ: UERJ. 
Coimbra, C. M. B. (s. d.). A ditadura militar brasileira (1964-1985) e a profissão da Psicologia. In Conselho Federal de Psicologia - CFP. Democratização no Sistema Conselhos de Psicologia: Mudanças na Lei 5.766/71. Brasília, DF: CFP.

Conselho Federal de Psicologia - CFP. Resolução CFP No 011/98, de 22 de novembro de 1998. Institui a Comissão de Direitos Humanos do Conselho Federal de Psicologia. Recuperado de http://www.crprs.org.br/upload/legislacao/legislacao7.pdf

Conselho Federal de Psicologia - CFP. (2005). Resolução CFP No 010/05, de 21 de julho de 2005. Aprova o Código de Ética Profissional do Psicólogo. Recuperado de http://site.cfp.org.br/wp-content/uploads/2012/07/codigo_etica.pdf

Costa, J. C., Oliveira, P. A., \& Ferraza, D. A. (2014). Psicologia social e direitos humanos: a atuação da psicologia diante ditadura militar e das manifestações atuais no Brasil. Revista de Psicologia da IMED, 6(2), 70-80. https://doi.org/10.18256/2175-5027/psico-imed.v6n2p70-80

Furlan, V., \& Pelissari, M. A. (2013). Psicologia e os contextos sócio-político-cultural e das políticas sociais no século XXI. Psicologia: Ciência e Profissão, 33(num. esp.): 24-30. Recuparado de http://www.scielo.br/scielo.php?scrip$\mathrm{t}=\mathrm{sci} \_$arttext\&pid=S1414-98932013000500004\&lng=en\&nrm=iso\&tlng=pt

Gil, A. C. (1987). Métodos e técnicas em pesquisa social. São Paulo, SP: Atlas.

Heller, A. (2008). O cotidiano e a história. (8a ed). São Paulo, SP: Paz e Terra.

Hur, D. U. (2007). A psicologia e suas entidades de classe: histórias sobre sua fundação e algumas práticas no Estado de São Paulo nos anos 70. Psicologia Política, 7(13). Recuperado de http://www.fafich.ufmg.br/rpp/seer/ ojs /viewarticle.php?id=17\&layout=html

Hur, D. U. (2012). Políticas da Psicologia: histórias e práticas das associações profissionais. Psicologia USP, 23(1), 69-90. https://doi.org/10.1590/S0103-65642012000100004

Hur, D. U., \& Lacerda Junior, F. (2016). Apresentação. In D. U. Hur, \& F. Lacerda Junior (Orgs.), Psicologia política crítica: insurgências na américa Latina (pp. 6-14. São Paulo, SP: Alínea.

Jacó-Vilela, A. M. (1999). Os primórdios da Psicologia Jurídica. In L. M. Brito (Org.), Temas de psicologia jurídica (pp. 11-17). Rio de Janeiro, RJ: Belume-Dumará.

Lacerda Junior, F. (2013). Capitalismo dependente e a psicologia no Brasil: das alternativas à psicologia crítica. Teoria y Crítica de la Psicologia, 3, 216-263. Recuperado de http://www.teocripsi.com/documents/3LACERDA.pdf

Lima, A. F., Ciampa, A. C., \& Almeida, J. A. M. (2009). Psicologia social como psicologia política? A proposta de psicologia social crítica de Sílvia Lane. Revista Psicologia Política, 9(18), 223-236. Recuperado de http://pepsic. bvsalud.org/scielo.php?script=sci_arttext\&pid=S1519-549X2009000200004

Oliveira, M. V. (2013). Entrevista com Marcus Vinícius de Oliveira. In Conselho Federal de Psicologia - CFP. A verdade é revolucionária: testemunhos e memórias de psicólogas e psicólogos sobre a ditadura civil-militar brasileira (1964-1985) (pp. 59-77). Brasília, DF: CFP.

Organização das Nações Unidas - ONU. Declaração Universal dos Direitos Humanos. Recuperado de http://portal. $\mathrm{mj}$.gov.br/sedh/ct/legis_intern/ddh_bib_inter_universal.htm

Patto, M. H. S. (2003). D. H. e a atuação na educação. In Conselho Federal de Psicologia - CFP, Comissão Nacional dos Direitos Humanos (Org.). Os direitos humanos na prática profissional dos Psicólogos (pp. 13-15) . Brasília, DF: CFP.

Pereira, E. H. P. (2007). Políticas públicas e Psicologia: potencialidades e desafios dessa relação. In Relatório do IV Seminário Nacional de Psicologia e Políticas Públicas. Maceió, AL: CFP/ULAPSI.

Peschanski, J. A. (2012). Os “ocupas” e a desigualdade econômica. In D. Harvey, E. Teles. \& E. Sader, Occupy: movimentos de protestos que ocuparam as ruas (pp. 27-30). São Paulo, SP: Boitempo.

Santos, B. S. (2012). Derechos humanos, democracia y desarollo. Bogotá, DC: Desjuticia.

Santos, B. S. (2013). Se Deus fosse um ativista dos direitos humanos. São Paulo, SP: Cortez.

Scarparo, H., \& Ozorio, J. C. (2009). Registros históricos do Conselho de Psicologia da Sétima Região (CRP-07) no período da Ditadura no Brasil. Temas em Psicologia, 17(1), 93-104. Recuperado de http://pepsic.bvsalud.org/ scielo.php?script=sci_arttext\&pid=S1413-389X2009000100009

Souza, T. R. P. (2015). Políticas públicas no enfoque da psicologia política. In A. S. Silva, \& F. Côrrea, No interstício das disciplinaridades: a psicologia política (pp. 29-238). Curitiba, PR: Prismas. 
Sposito, S. E. (2011). Notas sobre psicologia e direitos humanos no âmbito do Conselho Regional de Psicologia de São Paulo. In K. M. Dotto, P. C. Endo, \& S. Elana (Orgs.), Psicologia, violência e direitos humanos (pp. 15-21). São Paulo, SP: CRP-SP.

Teles, E. (2012). Democracia, segurança pública e coragem para agir na política. In D. Harvey, E. Teles, \& E. Sader. Occupy: movimentos de protestos que ocuparam as ruas (pp. 77-82). São Paulo, SP: Boitempo.

Yamamoto, O. H. (2012). 50 anos de profissão: responsabilidade social ou projeto ético-político? Psicologia: Ciência e Profissão, 32(num. esp.): 6-17. https://doi.org/10.1590/S1414-98932012000500002

\section{Vinicius Furlan}

Doutorando em Psicologia Social - PUC-SP. Mestre em Psicologia - UFC.

E-mail:vc_furlan@hotmail.com

Endereço para envio de correspondência:

Francisco Jorge de Moraes, 153, Santa Helena,

Charqueada - SP, Brasil.

CEP: 13515-000.

Recebido 30/06/2017

Reformulado 06/09/2017

Aprovado 20/09/2017

Received 06/30/2017

Reformulated $06 / 30 / 2017$

Approved 06/30/2017

Recebido 30/06/2017

Reformulado 06/09/2017

Aceptado 20/09/2017

Como citar: Furlan, V. (2017). Psicologia e a política de direitos: percursos de uma relação. Psicologia: Ciência e Profissão, 37(n. spe), 91-102. https://doi.org/10.1590/1982-3703070002017

How to cite: Furlan, V. (2017). Psychology and the rights policy: paths of a relationship. Psicologia: Ciência e Profissão, 37(n. spe), 91-102. https://doi.org/10.1590/1982-3703070002017

Cómo citar: Furlan, V. (2017). Psicología y política de derechos: caminos de una relación. Psicologia: Ciência e Profissão, 37(n. spe), 91-102. https://doi.org/10.1590/1982-3703070002017 